\title{
Prevalence of low back pain in Iranian nurses: a systematic review and meta- analysis
}

Yosra Azizpour ${ }^{1}$, Ali Delpisheh ${ }^{2}$, Zahra Montazeri ${ }^{3}$ and Kourosh Sayehmiri ${ }^{4^{*}}$

\begin{abstract}
Background: Low back pain (LBP) as a musculoskeletal disorder is one of the most common occupational injuries in nurses but there isn't any valid measure of the prevalence of LBP in Iranian nursing. In order to increase the power and improve the estimates of the prevalence of LBP in Iranian nurses, a comprehensive meta-analysis was carried out. A summary measure of all studies conducted in this field was found and distributions of LBP were evaluated based on different variables.
\end{abstract}

Methods: Inclusion criteria included articles with prevalence of LBP in Iranian nurses, who had at least six months of work experience without any trauma, injuries to spine, or any underlying disease. The keywords"prevalence, low back pain, nurses", and "Iran" were used as part of this search. Databases such as Pubmed, Web of Science, Science direct, Scopus, IranMedex, Irandoc, Magiran, SID, CIVILICA, IMEMR and Google scholar were searched up to and including 15 June 2016. For data extraction a form was designed that included the following variables: Author names, province, sample size, age, gender, marital status, work experience, body mass index, job type, smoking status, work schedule, year of publication, type of standard questionnaire, prevalence of LBP, studies' quality score and climate classifications. Data analysis was carried out using fixed and random effects model. Heterogeneity between studies was assessed by using the $\mathrm{I}^{2}$ and $\mathrm{Q}$ tests.

Results: In all 1250 articles were identified and 22 articles with 9347 participants met the inclusion criteria for metaanalyses after filtering. The prevalence of low back pain during their working life and during the last year, was estimated at 63\% (95\% Confidence Interval (CI): 57.4-68.5) and 61.2\% (95\% Cl: 55.7-66.7) respectively. The prevalence rate of this disorder was $58.7 \%$ (95\% Cl: $35.8-81.7)$ and $60.4 \%$ (95\% Cl: 52.2-68.6) among men and women respectively. Furthermore, prevalence's of LBP were $59.5 \%$ in wards nurses, $50.3 \%$ in operating room technicians, and $39.4 \%$ in aid nurses.

Conclusions: The results showed the high prevalence of LBP injury in nurses, especially female nurses. The effect of musculoskeletal disorders such as LBP may be reduced by considering proper observation of the principles of ergonomics in the workplace, performing physical examinations on a regular basis, identifying risk factors in the advancement of musculoskeletal disorders and then trying to fix them.

Keywords: Iran, Low back pain, Nurses, Meta-analysis

\footnotetext{
*Correspondence: sayehmiri@razi.tums.ac.ir

${ }^{4}$ Department of Biostatistics, Psychosocial Injuries Research Center, llam

University of Medical Sciences, Ilam, Iran

Full list of author information is available at the end of the article
} 


\section{Background}

Musculoskeletal disorders are one of the main issues that arise in the field of health. It is considered globally as the second leading cause of physical disability [1]. The study conducted in Iran that dealt with the burden of disease and injury, and ranked the "disability -adjusted life year" (DALY), indicated that low back pain was in the eighth place among all causes leading to damage including (natural and unnatural) incidences and in fourth place regardless of the latter, [2]. Musculoskeletal disorders are significant problems at work among nurses [3] and LBP is the most important musculoskeletal disorder among them with a rate of $30-60 \%$ [4]. Results of a systematic review carried out by Ellapen and Narsigan showed that musculoskeletal disorders in nurses were higher in the lower back, neck, and shoulders [5]. In the studies by Sikiru (Africa) [6] and Freimann (Estonia) [7], $70.87 \%$ and $57 \%$ of nurses suffered from low back pain during the preceding 12 month period respectively. The Skela-Savič study (Slovenia) indicated that the prevalence of LBP in nurses was $85.9 \%$ [8].

We note the negative impact of occupational low back pain. This includes, but is not restricted to, work absence, loss of optimal performance, rising medical costs of treatment and care and occupational disability [9]. Estimating LBP prevalence among nurses is essential for designing control plans and prevention programs. Given that there are no accurate statistics about the prevalence of LBP for nurses in Iran, accordingly, we were encouraged to conduct a study for estimating prevalence of LBP in Iranian nurses.

\section{Methods}

These systematic review and meta-analyses were conducted based on PRISMA guidelines [10].

\section{Characteristics of studies}

All research conducted in the field of LBP prevalence in Iranian nurses, regardless of the publication language (Farsi or English) and time span, were reviewed and included in our study.

\section{Definitions of variables}

Musculoskeletal disorders: Any pain or discomfort in one or more limbs.

Low back pain: Any pain in the lower back between L1 - L5 (lumbar spine) and L5-S1 (lumbosacral joint).

Nurses: Nurses employed in hospitals.

\section{Data sources}

A systematic literature search was conducted in international databases such as Web of Science (1983 to 15 June 2016), Science Direct (1823 to 15 June 2016), PubMed (1966 to 15 June 2016), Scopus (1960 to 15
June 2016), Google Scholar (web search engine), and national databases such as Magiran: an Iranian Journal Database (2001 to 15 June 2016); SID: Scientific Information Database (2000 to 15 June 2016); Iran Medex: an Iranian Biomedical Journal (1982 to 15 June 2016); Irandoc: Iranian Research Institute for Information Science and Technology (1970 to15 June 2016), CIVILICA (Publisher of specialized conferences within the country), (1999 to 15 June 2016); and regional databases including IMEMR: Index Medicus for Eastern Mediterranean Region (1984 to 15 June 2016). The keywords used for this search were "low back pain, musculoskeletal, nurses, prevalence", and "Iran". Furthermore, keywords with medical subject headings (MeSh) were used in "advanced searches" in international databases, and these keywords were combined through the use of conjunctions such as OR, AND, NOT. (Equivalents terms in Farsi were used in national databases). It should be noted that articles published in journals and/or conferences, reports, dissertations/theses and all other references to relevant articles were included in our searches.

\section{Study selection}

Inclusion criteria dealt with studies that present prevalence of LBP in nurses in Iran who had at least six months of work experience without any trauma, injuries to spine, or any underlying disease. Exclusion criteria included irrelevant studies, articles without adequate data regarding observations, studies that linked LBP with other diseases, and duplicate studies.

\section{Data extraction and study quality assessment}

Data extraction and study quality assessment was done by two independent researchers (Azizpour and Sayehmiri). Cases of disagreement were solved by a discussion between two reviewers. For data extraction a form was designed that included the following variables: Author names, province, sample size, age $(<45$ years old and $>45$ years old), gender (male/female), marital status (single/married), work experience (1-10 year, 11-20 year, 2130 year), body mass index (underweight $<20$, normal weight 20-25, overweight 25-30, obese $>30$ ), type of job (ward nurse, operating room technicians, and nursing aids), smoking status (yes/no), work schedule (shift work/ day work), year of publication, type of standard questionnaire, prevalence of LBP, studies' quality score. Climate classifications were defined as: 1.Cold climate, 2. Hot and dry climate 3.Temperate and humid climate [11]. Moreover, the adjusted odds ratio and associated confidence interval for variables of gender, work schedule, BMI and work experience was extracted. A modified critical appraisal tool was used to determine the quality and homogeneity of data. This tool includes three methodological tests containing 12 individual criteria for prevalence 
studies; three questions related to sample representativeness of the target population, six questions related to data quality, and three questions related to the definition of the low back pain disorder (Appendix) [12-14]. Studies with at least $75 \%$ of the total score were acceptable.

\section{Analytical approach}

Prevalence of LBP (during the working life and during the last year), in all studies were collected, and then the variance of having LBP was calculated according to the binomial distribution. The weight given to each study was assigned according to the inverse of the variance. Cochrane $\mathrm{Q}$ and $\mathrm{I}^{2}$ statistics were used to assess heterogeneity among studies. Heterogeneity was measured by $\mathrm{I}^{2}$ and divided into four categories; no heterogeneity $(0 \%)$, low (25-50\%), moderate (50-75\%), and high (>75\%) [15].

In this study we have two effect sizes (ES). The first effect size was prevalence. Due to the heterogeneity of the studies, we computed the prevalence of studies according to a random effects model. The second effect size was the odds ratio. To combine ORs at first we use the log transformation and then we compute Ln OR using the random effect model.

Subgroup analysis and meta-regression (the relationship between the years of the study with the prevalence rate) were employed to explore the cause of heterogeneity between studies. As well, a funnel plot (Begg's test) with pseudo 95\% confidence limits was used to examine publication bias. Data analysis was performed using STATA software version 11 (StataCorp, College Station, TX, USA). Significance level of 0.05 was considered for the $P$-value.

\section{Results}

In all 1250 articles were identified until 15 June 2016, all abstracts were reviewed and we excluded 1094 irrelevant and 100 duplicate studies. The full texts of the remaining 56 articles were reviewed in detail and finally 22 articles met the inclusion criteria for meta-analyses (Fig. 1). From these the total number of participants was

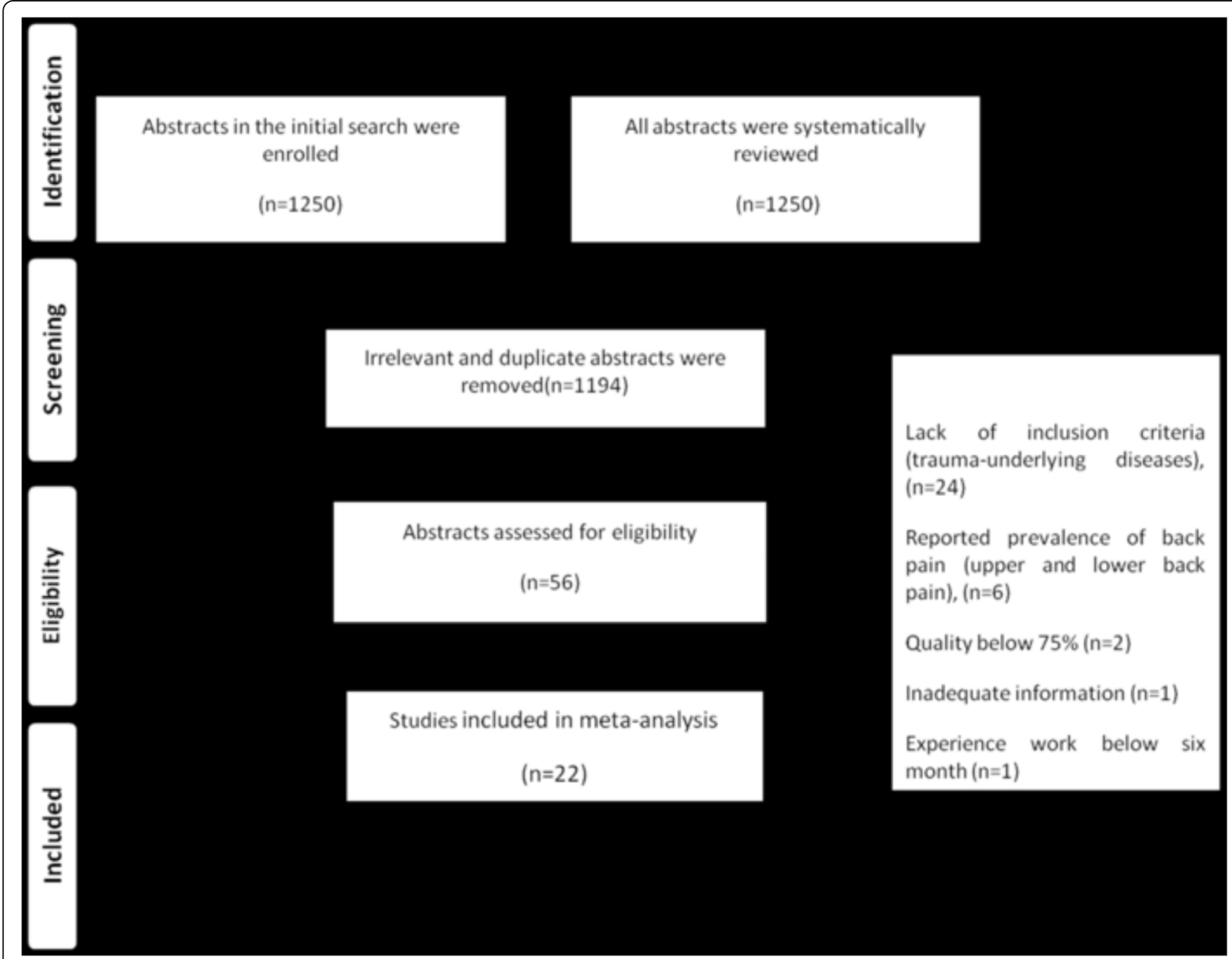

Fig. 1 Results of the systematic literature search 
9347 and twelve studies were written in English (Table 1). All articles were descriptive in nature with a quality score of higher than $80 \%$ (Table 2).

The prevalence of low back pain during a working life During the period 2013-2016 nine studies with a sample size of $(n=2564)$ have been carried out. Among them, the lowest and highest prevalence were found to be $45.8 \%$ and $76.1 \%$. The estimation of the prevalence rate via the random effects model was found to be $63 \%$ (95\% CI: 57.4-68.5; $P$-value $<0.0001)$. Heterogeneity of the reviewed studies was $\mathrm{I}^{2}=87.5$ and Heterogeneity chisquared $=64.10(\mathrm{~d} . \mathrm{f}=8) P$-value $<0.0001$ (highly heterogeneous) (Fig. 2).

\section{The prevalence of low back pain during the last year} During the period 2004-2016, thirteen studies with a sample size of $(n=6803)$ have been carried out. Among them, the lowest and the highest prevalence were found to be $40 \%$ and $78.3 \%$. The estimation of the prevalence rate via the random effects model was found to be $61.2 \%$ (95\% CI: 55.7-66.7; P-value < 0.0001). Heterogeneity of the reviewed studies was $\mathrm{I}^{2}=95.5$ and Heterogeneity chi-squared $=268.37(\mathrm{~d} . \mathrm{f}=12) P$-value $<0.0001$ (highly heterogeneous) (Fig. 3).

\section{Subgroup analysis}

According to subgroup analyses, female and married nurses with prevalence rates of $60.4 \%$ (95\% CI: $52.2-$ 68.6; $P$-value $<0.0001)$ and $74.2 \%$ (95\% CI: 69-79.4; Pvalue $<0.0001$ ) had the higher prevalence of LBP as compared to their male counterparts, 58.7\% (95\% CI: $35.8-$ 81.7; P-value $<0.0001)$ and single nurses, $71.3 \%$ (95\% CI: 67.7-75; P-value <0.0001) respectively. Prevalence of LBP among nurses aged over 45 years, and less than 45 years, were $66 \%$ and $54.5 \%$ respectively ( $P$-value $<0.0001)$. Among nurses with $21-30$ years of experience, it was 60\% (95\% CI: $15-104.9 ; P$-value $<0.009)$, but in nurses with experience 1-10 years, the disorder rate was lower (53\%). Based on BMI variable, obese nurses and overweight nurses, had prevalence rates of $72.7 \%$ (95\% CI: 43.7-101.7) and $65.2 \%(95 \%$ CI: 50-80.4) with a higher level of pain in the lower back area as compared to nurses with normal weight and underweight (56.4\% and $48.2 \%)$, respectively ( $P$-value $<0.0001)$. Prevalence of LBP was $59.5 \%$ among ward nurses, $50.3 \%$ among operating room technicians, and $39.4 \%$ among nursing

Table 1 Characteristics of studies included in systematic review and meta-analysis of prevalence of low back pain in Iranian nurses

\begin{tabular}{|c|c|c|c|c|c|c|c|}
\hline Author & Province & Sample Size & Gender (\%) & Age & Year & Region of Pain & Measures \\
\hline Mosadeghrad [27] & Isfahan & 499 & 68.5 female & $<20-50+$ year & 2004 & LBP & Self-made questionnaire \\
\hline Sadeghian [28] & Semnan & 235 & 78.3 female & 19-50 year & 2005 & LBP & Nordic Questionnaire \\
\hline Mohseni-Bandpei [29] & Mazandran & 1226 & 81.9 female & 22-57 year & 2006 & $\begin{array}{l}\text { LBP and the } \\
\text { sacroiliac joints }\end{array}$ & Self-made questionnaire \\
\hline Choobineh [30] & Fars & 641 & 84.7 female & 22-66 year & 2006 & LBP & Nordic Questionnaire \\
\hline Choobineh [31] & Fars & 375 & 66.4 female & 19-62 year & 2010 & LBP & Nordic Questionnaire \\
\hline Abedini [32] & Fars & 400 & 89.8 female & $30.78 \pm 6.44$ year & 2012 & LBP & Nordic Questionnaire \\
\hline Eftekhar Sadat [33] & Tabriz & 195 & 85.6 female & 23-53 year & 2013 & LBP & Be changed Dutch Questionnaire \\
\hline Raeisi [22] & Tehran & 477 & 78.4 female & 20-60 year & 2013 & LBP & Nordic Questionnaire \\
\hline Golabadi [26] & Tehran & 545 & 79.4 female & $32.1 \pm 7$ year & 2013 & LBP & Nordic Questionnaire \\
\hline Attarchi [34] & Tehran & 454 & 76 female & 20-55 year & 2014 & LBP & Nordic Questionnaire \\
\hline Ghasemi [35] & Isfahan & 244 & 68.9 female & N/A & 2014 & LBP & (VAS) and (ODQ) Questionnaire \\
\hline Arsalani [36] & Tehran & 520 & 79.4 female & $<30-40+$ year & 2014 & LBP & Adapted questionnaire \\
\hline Pahlevan [37] & Semnan & 286 & 73.5 female & 21-52 year & 2014 & LBP & Nordic Questionnaire \\
\hline Rezaee [38] & Tehran & 1246 & 53.7 female & 20-61 year & 2014 & LBP & Self-made questionnaire \\
\hline Zarrin Ghabaee [39] & Mazandran & 940 & 73.6 female & $33.7 \pm 8.07$ & 2015 & LBP & Nordic Questionnaire \\
\hline Dehdashti [40] & Semnan & 48 & 83.4 female & $24-50$ & 2015 & LBP & Nordic Questionnaire \\
\hline Habibi [41] & Isfahan & 247 & 91 female & 23-67 year & 2015 & LBP & Cornell Questionnaire \\
\hline Azma [42] & Tehran & 144 & 50.7 male & 27-43 year & 2015 & LBP & Cornell Questionnaire \\
\hline Rokni [43] & Mazandran & 110 & 88.2 female & 21-50 year & 2016 & LBP & Nordic Questionnaire \\
\hline Taghinejad [44] & Ilam & 135 & 58.5 female & 20-59 year & 2016 & LBP & Nordic Questionnaire \\
\hline Saremi [45] & Tehran & 30 & 80 female & 25-42 year & 2016 & LBP & Nordic Questionnaire \\
\hline Asadi [9] & Gilan & 350 & 90.3 female & 22-56 year & 2016 & LBP & Pre-designed checklist \\
\hline
\end{tabular}


Table $\mathbf{2}$ Investigation of the quality of studies via modified critical appraisal tools

\begin{tabular}{|c|c|c|c|c|c|c|c|c|c|c|c|c|c|}
\hline Author & 1 & 2 & 3 & 4 & 5 & 6 & 7 & 8 & 9 & 10 & 11 & 12 & Total Score\% \\
\hline Mosadeghrad [27] & $\sqrt{ }$ & $\sqrt{ }$ & $\sqrt{ }$ & $\sqrt{ }$ & $\sqrt{ }$ & $\sqrt{ }$ & $\sqrt{ }$ & NA & NA & $\sqrt{ }$ & $x$ & $\sqrt{ }$ & 90 \\
\hline Sadeghian [28] & $\sqrt{ }$ & $\sqrt{ }$ & $\sqrt{ }$ & $\sqrt{ }$ & $\sqrt{ }$ & $\sqrt{ }$ & $\sqrt{ }$ & NA & $x$ & $\sqrt{ }$ & $\sqrt{ }$ & $\sqrt{ }$ & 91 \\
\hline Mohseni-Bandpei [29] & $\sqrt{ }$ & $\sqrt{ }$ & $\sqrt{ }$ & $\sqrt{ }$ & $\sqrt{ }$ & $\sqrt{ }$ & $x$ & NA & NA & $\sqrt{ }$ & $\sqrt{ }$ & $\sqrt{ }$ & 90 \\
\hline Choobineh [30] & $\sqrt{ }$ & $\sqrt{ }$ & $\sqrt{ }$ & $\sqrt{ }$ & $\sqrt{ }$ & $\sqrt{ }$ & $\sqrt{ }$ & NA & NA & $\sqrt{ }$ & $x$ & $\sqrt{ }$ & 90 \\
\hline Choobineh [31] & $\sqrt{ }$ & $\sqrt{ }$ & $\sqrt{ }$ & $\sqrt{ }$ & $\sqrt{ }$ & $\sqrt{ }$ & $\sqrt{ }$ & NA & NA & $\sqrt{ }$ & $x$ & $\sqrt{ }$ & 90 \\
\hline Abedini [32] & $\sqrt{ }$ & $\sqrt{ }$ & $\sqrt{ }$ & $\sqrt{ }$ & $\sqrt{ }$ & $\sqrt{ }$ & $\sqrt{ }$ & NA & NA & $\sqrt{ }$ & $\times$ & $\sqrt{ }$ & 90 \\
\hline Eftekhar Sadat [33] & $\sqrt{ }$ & $\sqrt{ }$ & $\sqrt{ }$ & $\sqrt{ }$ & $\sqrt{ }$ & $\sqrt{ }$ & $x$ & NA & NA & $\sqrt{ }$ & $\sqrt{ }$ & $\sqrt{ }$ & 90 \\
\hline Raeisi [22] & $\sqrt{ }$ & $\sqrt{ }$ & $\sqrt{ }$ & $\sqrt{ }$ & $\sqrt{ }$ & $\sqrt{ }$ & $\sqrt{ }$ & NA & NA & $\sqrt{ }$ & $x$ & $\sqrt{ }$ & 90 \\
\hline Golabadi [26] & $\sqrt{ }$ & $\sqrt{ }$ & $\sqrt{ }$ & $\sqrt{ }$ & $\sqrt{ }$ & $\sqrt{ }$ & $\sqrt{ }$ & NA & NA & $\sqrt{ }$ & $x$ & $\sqrt{ }$ & 90 \\
\hline Attarchi [34] & $\sqrt{ }$ & $\checkmark$ & $\sqrt{ }$ & $\sqrt{ }$ & $\sqrt{ }$ & $\sqrt{ }$ & $\sqrt{ }$ & NA & NA & $\sqrt{ }$ & $x$ & $\sqrt{ }$ & 90 \\
\hline Ghasemi [35] & $\sqrt{ }$ & $\checkmark$ & $\sqrt{ }$ & $\sqrt{ }$ & $\sqrt{ }$ & $\sqrt{ }$ & $\sqrt{ }$ & NA & $\sqrt{ }$ & $\sqrt{ }$ & $\sqrt{ }$ & $\sqrt{ }$ & 100 \\
\hline Arsalani [36] & $\checkmark$ & $\sqrt{ }$ & $\sqrt{ }$ & $\sqrt{ }$ & $\sqrt{ }$ & $\sqrt{ }$ & $\sqrt{ }$ & NA & NA & $\sqrt{ }$ & $x$ & $\sqrt{ }$ & 90 \\
\hline Pahlevan [37] & $\sqrt{ }$ & $\sqrt{ }$ & $\checkmark$ & $\sqrt{ }$ & $\sqrt{ }$ & $\sqrt{ }$ & $\sqrt{ }$ & NA & NA & $\sqrt{ }$ & $x$ & $\sqrt{ }$ & 90 \\
\hline Rezaee [38] & $\sqrt{ }$ & $\sqrt{ }$ & $\sqrt{ }$ & $\sqrt{ }$ & $\sqrt{ }$ & $\sqrt{ }$ & $x$ & NA & NA & $\sqrt{ }$ & $\sqrt{ }$ & $\sqrt{ }$ & 90 \\
\hline Zarrin Ghabaee [39] & $\checkmark$ & $\checkmark$ & $\sqrt{ }$ & $\sqrt{ }$ & $\sqrt{ }$ & $\sqrt{ }$ & $\sqrt{ }$ & NA & NA & $\sqrt{ }$ & $\times$ & $\sqrt{ }$ & 90 \\
\hline Dehdashti [40] & $\checkmark$ & $\sqrt{ }$ & $\sqrt{ }$ & $\sqrt{ }$ & $\sqrt{ }$ & $\sqrt{ }$ & $\sqrt{ }$ & NA & NA & $\sqrt{ }$ & $x$ & $\sqrt{ }$ & 90 \\
\hline Habibi [41] & $\checkmark$ & $\sqrt{ }$ & $\checkmark$ & $\sqrt{ }$ & $\sqrt{ }$ & $\sqrt{ }$ & $\sqrt{ }$ & NA & $\sqrt{ }$ & $\sqrt{ }$ & $\sqrt{ }$ & $\sqrt{ }$ & 100 \\
\hline Azma [42] & $\checkmark$ & $\checkmark$ & $\checkmark$ & $\sqrt{ }$ & $\sqrt{ }$ & $\sqrt{ }$ & $\sqrt{ }$ & NA & $\sqrt{ }$ & $\sqrt{ }$ & $\sqrt{ }$ & $\sqrt{ }$ & 100 \\
\hline Rokni [43] & $\checkmark$ & $\checkmark$ & $\checkmark$ & $\sqrt{ }$ & $\sqrt{ }$ & $\sqrt{ }$ & $\sqrt{ }$ & NA & NA & $\sqrt{ }$ & $x$ & $\sqrt{ }$ & 90 \\
\hline Taghinejad [44] & $\checkmark$ & $\checkmark$ & $\checkmark$ & $\sqrt{ }$ & $\sqrt{ }$ & $\sqrt{ }$ & $\sqrt{ }$ & NA & NA & $\sqrt{ }$ & $\times$ & $\sqrt{ }$ & 90 \\
\hline Saremi [45] & $\checkmark$ & $\sqrt{ }$ & $\checkmark$ & $\sqrt{ }$ & $\sqrt{ }$ & $\sqrt{ }$ & $\sqrt{ }$ & NA & $\sqrt{ }$ & $\sqrt{ }$ & $\sqrt{ }$ & $\sqrt{ }$ & 100 \\
\hline Asadi [9] & $\sqrt{ }$ & $\sqrt{ }$ & $\sqrt{ }$ & $\sqrt{ }$ & $\sqrt{ }$ & $\sqrt{ }$ & $x$ & NA & NA & $\sqrt{ }$ & $x$ & $\sqrt{ }$ & 80 \\
\hline
\end{tabular}

Author

Eftehar Sadat $2013 \quad 195 \quad 138$

$\begin{array}{llll}\text { Ghasemi } & 2014 \quad 244 & 135\end{array}$

Pahlevan $\quad 2014 \quad 286 \quad 189$

Zarrn Ghabaee $2015940 \quad 572$

Dehdasht $\quad 2015 \quad 48 \quad 28$

$\begin{array}{llll}\text { Habbi } & 2015 \quad 247 & 188\end{array}$

Azma $\quad 2015 \quad 144 \quad 66$

$\begin{array}{llll}\text { Asadi } & 2016 \quad 350 \quad 246\end{array}$

Rokni $\quad 2016 \quad 110 \quad 64$

Overall (1-squared $=87.5 \%, p=0.000)$

NOTE Weights are from random effects analysis
$071(064,077) 11.48$

$0.55(0.49 .0 .62) 11.56$

$0.66(0.61,0.72) 11.95$

$0.61(0.58 .0 .64) 12.96$

$0.58(0.44,0.72) 7.34$

$0.76(0.71,0.81) 12.03$

$0.46(0.38,0.54) 10.50$

$0.70(0.66,0.75) 12.29$

$0.58(0.49,0.67) 9.88$

$0.63(0.57,0.69) 100.00$

Fig. 2 Prevalence of LBP in Iranian nurses during the working life 


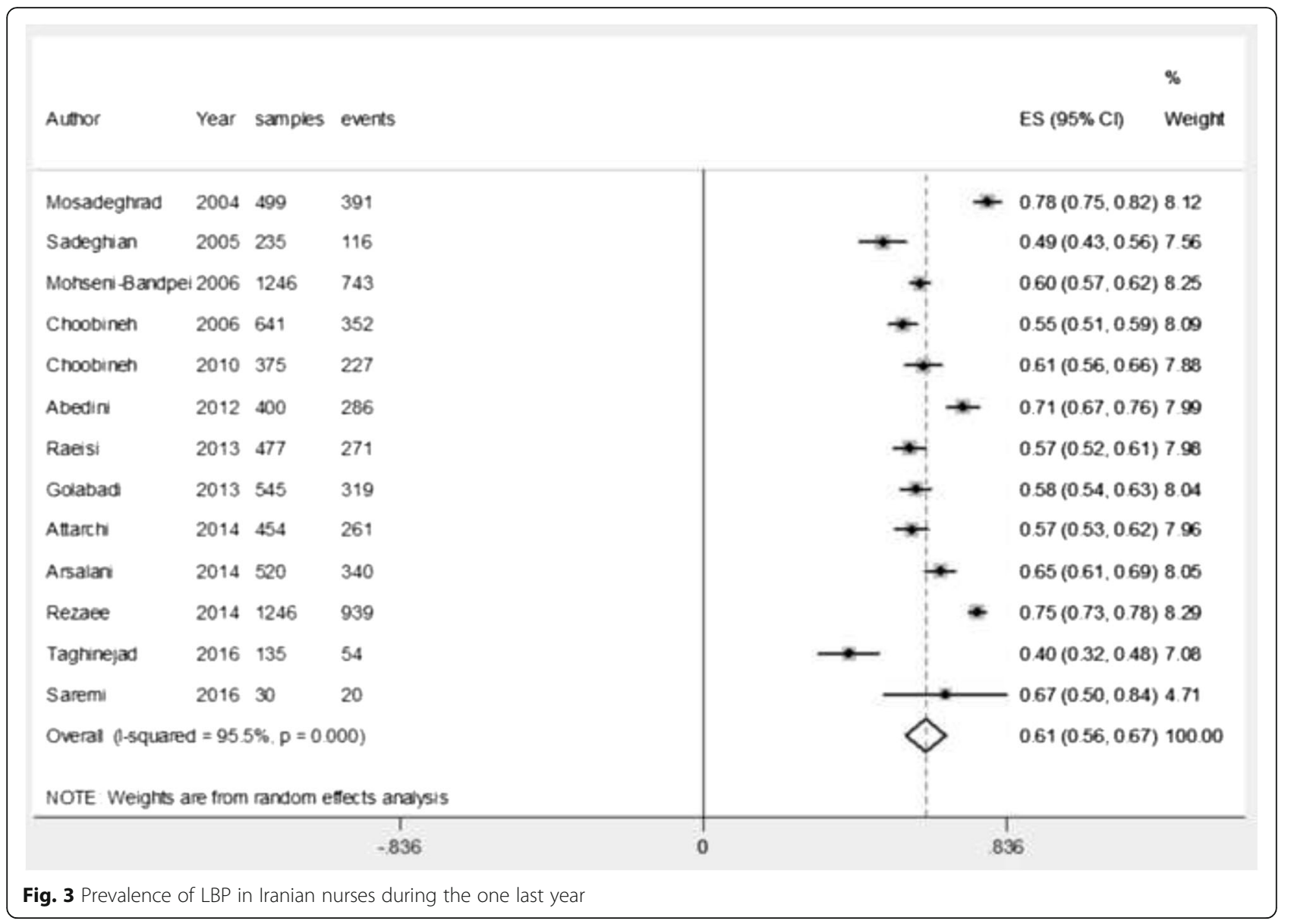

aids. The rate of LBP was higher among non-smokers, i.e., $73.6 \%$ (95\% CI: $68.8-78.5$; $P$-value $<0.0001$ ) in comparison to smokers (Table 3). Furthermore, the prevalence of LBP in a hot /dry climate was 63.7\% (95\% CI: 56.5-70.8) as well as in the temperate/humid climate, while in a cold climate it was $62.5 \%$ (95\% CI: 57.7-67.2) and 59.7\% (95\% CI: 52.3-67.1) respectively.

\section{Effect size of adjusted OR}

The risk of LBP in women was 2.44 times more likely than the risk in men $(\mathrm{OR}=2.44 ; 95 \% \mathrm{CI}: 1.89-3.14, P$ value <0.0001). In nurses with $\mathrm{BMI}>25$, it was 1.21 times more likely than those with BMI $<25$ (OR = 1.21; 95\% CI: 0.84-1.74, P-value <0.302). In nurses with over 7 years of work experience it was 2.61 times more likely than those nurses with less than 7 years' experience $(\mathrm{OR}=2.61$; 95\% CI: 2.02-3.37, $P$-value <0.0001). Finally, for those nurses in shift work it was 1.84 times more likely than those involved in day work $(\mathrm{OR}=2.44 ; 95 \%$ CI: 1.43-2.37, P-value <0.0001).

\section{Meta -regression}

Meta-regression analysis showed that there was no significant statistical relationship between the year of publication and the prevalence of the LBP $(P$-value $=0.812)$ (Fig. 4).

\section{Publication bias}

Based on the Beggs test, the $p$-value of bias for the studies related to prevalence of low back pain in Iranian nurses is 0.446 (Fig. 5). This identified that the publication bias was not significant.

\section{Discussion}

Overall, the prevalence rate of LBP during a working life and during the previous year was $63 \%$ and $61.2 \%$ respectively, which indicated a relatively high prevalence. Annual prevalence of LBP in Swiss nurses was found to be $73-76 \%$ [16], in comparison with Italian nurses, 86\% [17], while in Nigerian nurses it was $44.1 \%$ [3], and finally in Japanese nurses it was $71.3 \%$ [18] respectively. A comparison of the results revealed that the annual prevalence of LBP among Iranian nurses was lower than Swiss, Japanese and Italian nurses and higher than Nigerian nurses. In nursing practice in many developed countries, due no doubt to the high workloads for patient care, one of the important health concerns is LBP [19]. 
Table 3 Prevalence of low back pain in Iranian nurses according to demographic variables

\begin{tabular}{|c|c|c|c|c|}
\hline \multirow[t]{2}{*}{ Variables } & \multirow{2}{*}{$\begin{array}{l}\text { Prevalence } \\
(\%)\end{array}$} & \multicolumn{2}{|c|}{ Confidence Interval (\%) } & \multirow[t]{2}{*}{$P$-value } \\
\hline & & lower & upper & \\
\hline \multicolumn{5}{|l|}{ Age } \\
\hline$<45$ year & 54.5 & 44.1 & 65 & 0.0001 \\
\hline$>45$ year & 66 & 63.7 & 68.3 & 0.0001 \\
\hline \multicolumn{5}{|l|}{ Gender } \\
\hline Female & 60.4 & 52.2 & 68.6 & 0.0001 \\
\hline Male & 58.7 & 35.8 & 81.7 & 0.0001 \\
\hline \multicolumn{5}{|l|}{ Marital status } \\
\hline Single & 71.3 & 67.7 & 75 & 0.0001 \\
\hline Married & 74.2 & 69 & 79.4 & 0.0001 \\
\hline \multicolumn{5}{|l|}{ Work experience } \\
\hline $1-10$ & 53 & 28.8 & 77.2 & 0.0001 \\
\hline $11-20$ & 58.3 & 23.6 & 93 & 0.001 \\
\hline $21-30$ & 60 & 15 & 104.9 & 0.009 \\
\hline \multicolumn{5}{|l|}{ BMl } \\
\hline$<20$ & 48.2 & 35.3 & 61.1 & 0.0001 \\
\hline $20-25$ & 56.4 & 37 & 75.8 & 0.0001 \\
\hline $25-30$ & 65.2 & 50 & 80.4 & 0.0001 \\
\hline$>30$ & 72.7 & 43.7 & 101.7 & 0.0001 \\
\hline \multicolumn{5}{|l|}{ Nursing job } \\
\hline Wards nurses & 59.5 & 53.3 & 65.7 & 0.0001 \\
\hline Operating room technicians & 50.3 & 39 & 61.6 & 0.0001 \\
\hline Aids & 39.4 & 19.9 & 58.9 & 0.0001 \\
\hline \multicolumn{5}{|l|}{ Smoking status } \\
\hline Yes & 61.1 & 39.6 & 82.7 & 0.0001 \\
\hline No & 73.6 & 68.8 & 78.5 & 0.0001 \\
\hline
\end{tabular}

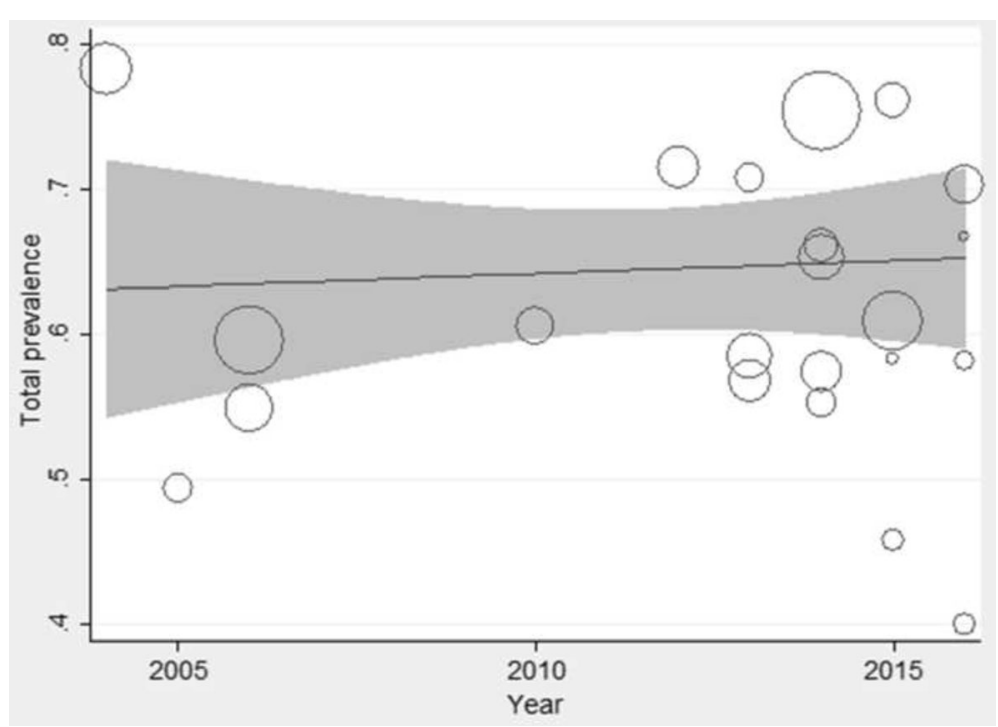

Fig. 4 Investigation of the relationship between the year of publication and the prevalence of LBP in Iranian nurses via meta-regression 


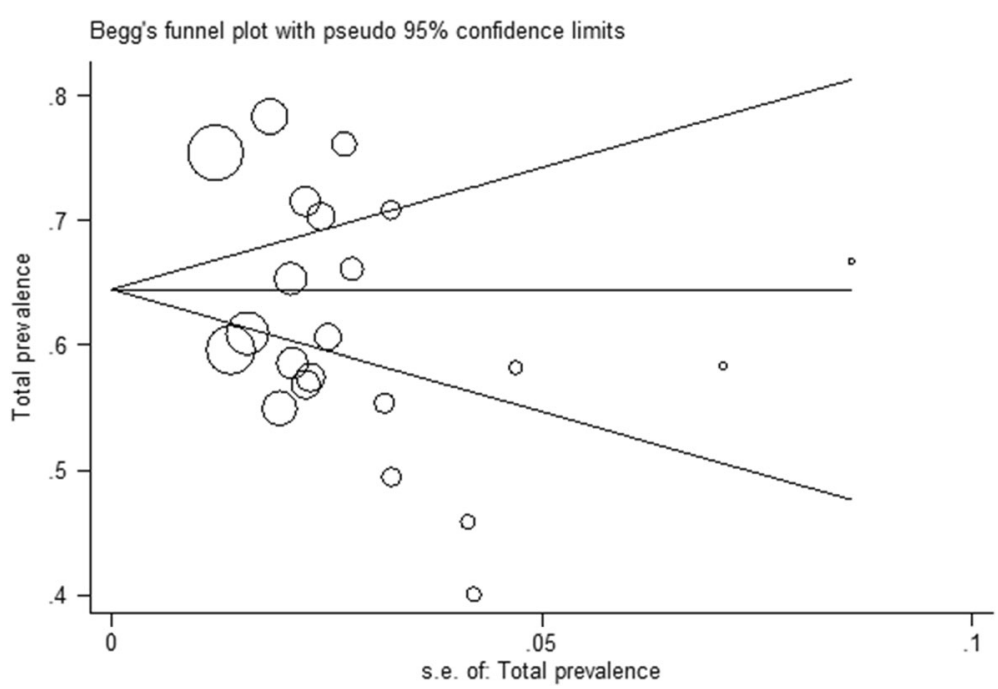

Fig. 5 Begg's funnel plot (pseudo 95\% confidence limits) showings significant level of publication bias

The results of our study confirmed that the prevalence of LBP in ward nurses is higher than the other groups. In Saudi Arabia, a study conducted on operating room staff revealed that the prevalence of back pain among nurses (anesthesia technician, nurse and operating room technician) was higher than $60 \%$ [20], a result that is almost similar to those obtained in our study. The results in Karahan et al. (Turkey) showed that, the prevalence of LBP was $77.1 \%$ in nurses, $69.6 \%$ in technicians and $53.5 \%$ in hospital aides [21]. In another study, Raeisi and colleagues found that the prevalence of LBP in ward nurses was $62.9 \%$, for operating room nurses it found $50 \%$, while in aids nurses it was $49.4 \%$ [22]. These results also confirmed the results of our study.

The evidence in this study indicated that prevalence of LBP in nurses over 45 years old with high work experience was higher than any other group. With aging the power of the body (mental and physical) will decrease. In healthcare workers who are also elderly, back pain is a common health problem [23].

The results of this study identified the high prevalence of back pain disorder in women and married nurses in comparison to men and single nurses. As mentioned before the risk of LBP in women was 2.44 times than the corresponding risk in men. It seems factors such as specific physical conditions in women, e.g. lower pain threshold, and physical changes due to monthly menstruation, can be a reason for such disorders in women [24]. In three recent studies married nurses and women nurses in Saudi Arabia [25], single nurses in Taiwan [19], and female nurses in Slovenia [8] had higher rates of low back pain prevalence. In fact, the results of these studies were in agreement with our results with respect to gender, but with respect to marital status, the first study was in agreement whereas the third study was in contrast with ours.

In this study it was observed that demographic factors such as BMI $>30$ percentile (obesity), work shift (working other than normal hours during a day), gender (women), marital status (married), high work experience, were significantly associated with LBP. However, it was not possible to identify the effects of the physical and mental factors on LBP due to the lack of related information. Golabadi et al. indicated that after adjusting confounding factors among physical demands, awkward position (high status) and static standing posture (high status), psychosocial demands (high status) were highly associated to LBP. Also the nature of the schedule of work (shift work), work experience ( $>7$ years) and gender (female) were significantly associated with prevalence of LBP among nurses [26]. It was shown in another study in Turkey that factors such as age $(69.4 \%$ in age group 17-24), gender (70\% in female), level of education (70.4\% in academic level), stand in a day's work $(73.6 \%>8 \mathrm{~h})$, perception of stress $(75.7 \%$ in level of very severe) and lifting or carrying heavy objects, had a significant relationship with the occurrence of LBP among hospital staff [21].

Conducting a study at national levels in order to determine psychological and physical stressors in the work environment of nurses and their relationship with musculoskeletal disorders, particularly LBP, to identify the risk factors and to design detailed plans for the prevention and control of these disorders, seems necessary. 


\section{Limitations}

The database for gray literature in Iran such as Irandoc was not comprehensive or maybe some researches were done in Iran but they don't include the results in this database. The structure of report in articles was not same. So that we could not access association some of risk factors with low back pain. For example, in working schedule variable, it was not report in the some articles.

\section{Conclusion}

The results herein showed the high prevalence of low back injury among (Iranian) nurses, especially in female nurses. Proper observation of the principles of ergonomics in the workplace, performing physical examinations on a regular basis, identifying risk factors in the advancement of musculoskeletal disorders, and trying to fix them can be effective factors in reducing musculoskeletal disorders such as back pain among nurses.

\section{Appendix}

Table 4 The critical appraisal tool

$\mathrm{A}$ : Is the final sample representative of the target population?

1. At least one of the following must apply in the study: an entire target population, randomly selected sample, or sample stated to represent the target population

2. At least one of the following: reasons for non response described, non responders described, comparison of responders and non responders, or comparison of sample and target population.

3. Response rate and, if applicable, drop-out rate reported.

B: Quality of the data?

4. Were the data primary data of low back pain or was it taken from a survey not specifically designed for that purpose?

5. Were the data collected from each adult directly or were they collected from a proxy?

6. Was the same mode of data collection used for all subjects?

7. At least one of the following in case of questionnaire: a validated questionnaire or at least tested for reproducibility.

8. At least one of the following in the case of an interview: Interview validated, tested for reproducibility, or adequately described and standardized.

9. At least one of the following in the case of an examination: Examination validated, tested for reproducibility, or adequately described and standardized.

C: Definition of low back pain (LBP)

10. Was there a precise anatomic delineation of the lumbar area or reference to an easily obtainable article that contains such specification?

11. Was there further useful specification of the definition of LBP, or question(s) put to study subjects quoted such as the frequency, duration or intensity, and character of the pain. Or was there reference to an easily obtainable article that contains such specification?

12. Were recall periods clearly stated: e.g., 1 week, 1 month or lifetime?

\section{Acknowledgments}

The Student Research Committee of Ilam University of Medical Science has supported this study.

\section{Funding}

This research was supported by the "Student Research Committee" of llam University of Medical Science (Number: 958037.111).

\section{Availability of data and materials}

Datasets are available through the corresponding author upon reasonable request.

\section{Authors' contributions}

YA and KS contributed to the design, statistical analysis, participated in most of the study steps, and prepared the manuscript. AD and ZM assisted in designing the study, and helped in the, interpretation of the study. All authors have read and approved the content of the manuscript.

\section{Ethics approval and consent to participate}

This study was approved by the Ethics Committee of Ilam University of Medical Sciences. Ethics number was "ir.medilam.rec.1395.136".

\section{Consent for publication}

Not applicable.

Competing interests

The authors declare that they have no conflict of interest.

\section{Publisher's Note}

Springer Nature remains neutral with regard to jurisdictional claims in published maps and institutional affiliations.

\section{Author details}

${ }^{1}$ Department of Clinical Epidemiology, Student Research Committee, Ilam University of Medical Sciences, Ilam, Iran. ${ }^{2}$ Department of Clinical Epidemiology, Psychosocial Injuries Research Center, llam University of Medical Sciences, Ilam, Iran. ${ }^{3}$ School of Epidemiology, Public Health and Preventive Medicine, Faculty of Medicine, University of Ottawa, Ottawa, Canada. ${ }^{4}$ Department of Biostatistics, Psychosocial Injuries Research Center, Ilam University of Medical Sciences, Ilam, Iran.

Received: 21 April 2017 Accepted: 1 September 2017

Published online: 11 September 2017

\section{References}

1. Vos T, Flaxman AD, Naghavi M, Lozano R, Michaud C, Ezzati M, et al. Years lived with disability (YLDs) for 1160 sequelae of 289 diseases and injuries 1990-2010: a systematic analysis for the global burden of disease study 2010. Lancet. 2012;380(9859):2163-96. doi: 10.1016/S0140-6736(12)61729-2.

2. Naghavi M, Abolhassani F, Pourmalek F, Moradi Lakeh M, Jafari N, Vaseghi S, et al. The burden of disease and injury in Iran 2003. Popul Health Metr. 2009:7:9 doi: 10.1186/1478-7954-7-9.

3. Tinubu BM, Mbada CE, Oyeyemi AL, Fabunmi AA. Work-related musculoskeletal disorders among nurses in Ibadan. South-west Nigeria: a cross-sectional survey BMC Musculoskelet Disord. 2010;11:12. doi: 10.1186/ 471-2474-11-12.

4. Moreira RF, Sato TO, Foltran FA, Silva LC, Coury HJ. Prevalence of musculoskeletal symptoms in hospital nurse technicians and licensed practical nurses: associations with demographic factors. Braz J Phys Ther. 2014;18(4):323-33

5. Ellapen TJ, Narsigan S. Work related musculoskeletal disorders among nurses: systematic review. J Ergon. 2014;S4:S4-003. doi: 10.4172/2165-7556. S4-003.

6. Sikiru L, Shmaila H. Prevalence and risk factors of low back pain among nurses in Africa: Nigerian and Ethiopian specialized hospitals survey study. East Afr J Public Health. 2009;6(1):22-5.

7. Freimann T, Pääsuke M, Merisalu E. Work-related psychosocial factors and mental health problems associated with musculoskeletal pain in nurses: a cross-sectional study. Pain Res Manag. 2016:2016:9361016. doi: 10.1155/ 2016. 
8. Skela-Savič B, Pesjak K, Hvalič-Touzery S. Low back pain among nurses in Slovenian hospitals: cross-sectional study. Int Nurs Rev. 2017:doi: 10.1111/inr. 12376. [Epub ahead of print].

9. Asadi P, Monsef Kasmaei V, Zia Ziabari S, Zohrevandi B. The prevalence of low back pain among nurses working in Poursina hospital in Rasht, Iran. J Emerg Pract Trauma. 2016;2(1):11-5. doi: 10.15171/jept.2015.01.

10. Moher D, Liberati A, Tetzlaff J, Altman DG, PRISMA Group. Preferred reporting items for systematic reviews and meta-analyses: the PRISMA statement. PLoS Med. 2009; 6(6): e1000097. doi: 10.1371/journal.pmed 1000097.

11. Kasmaei M. Climate and Architecture. Isfahan: khak; 2006. p. 83

12. Walker BF. The prevalence low back pain: a systematic review of the literature from 1966 to 1998. J Spinal Disord. 2000;13(3):205-17.

13. Mousavi SJ, Akbari ME, Mehdian H, Mobini B, Montazeri A, Akbarnia B, et al. Low back pain in Iran: a growing need to adapt and implement evidencebased practice in developing countries. Spine (Phila Pa 1976).2011;36(10): E638-46. doi: 10.1097/BRS.0b013e3181fa1da2

14. Louw QA, Morris LD, Grimmer-Somers K. The prevalence of low back pain in Africa: a systematic review. BMC Musculoskelet Disord. 2007;8:105. doi: 10. 1186/1471-2474-8-105

15. Ades $A E, L u G$, Higgins JP. The interpretation of random-effects metaanalysis in decision models. Med Decis Mak. 2005;25:646-54.

16. Maul I, Läubli T, Klipstein A, Krueger H. Course of low back pain among nurses: a longitudinal study across eight years. Occup Environ Med. 2003; 60(7):497-503. doi: 10.1136/oem.60.7.497.

17. Corona G, Amedei F, Miselli F, Padalino MP, Tibaldi S, Franco G. Association between relational and organizational factors and occurrence of musculoskeletal disease in health personnel. G Ital Med Lav Ergon. 2005; 27(2):208-12.

18. Smith DR, Mihashi M, Adachi Y, Koga H, Ishitake T. A detailed analysis of musculoskeletal disorder risk factors among Japanese nurses. J Saf Res. 2006;37(2):195-200. doi: 10.1016/j.jsr.2006.01.004

19. Shieh SH, Sung FC, Su CH, Tsai Y, Hsieh VC. Increased low back pain risk in nurses with high workload for patient care: a questionnaire survey. Taiwan J Obstet Gynecol. 2016;55(4):525-9. doi: 10.1016/j.tjog.2016.06.013.

20. Bin Homaid M, Abdelmoety D, Alshareef W, Alghamdi A, Alhozali F, Alfahmi $\mathrm{N}$, et al. Prevalence and risk factors of low back pain among operation room staff at a tertiary care center, Makkah. Saudi Arabia:a cross-sectional study Ann Occup Environ Med. 2016;28:1. doi:10.1186/s40557-016-0089-0.

21. Karahan A, Kav S, Abbasoglu A, Dogan N. Low back pain: prevalence and associated risk factors among hospital staff. J Adv Nurs. 2009;65(3):516-24. doi: 10.1111/j.365-2648.008.04905.x.

22. Raeisi S, Hosseini M, Attarchi MS, Golabadi M, Rezaei MS, Namvar M. The association between job type and ward of service of nursing personnel and prevalence of musculoskeletal disorders. Razi J Med Sci. 2013;20(108):1-10.

23. Fragar LJ, Depczynski JC. Beyond 50. challenges at work for older nurses and allied health workers in rural Australia: a thematic analysis of focus group discussions. BMC Health Serv Res. 2011:11:42. doi: 10.1186/472-6963$11-42$

24. Ísper Garbin AJ, Saliba Garbin CA, Arcieri RM, Saliba Rovida TA. Da Graça Fagundes Freire AC. Musculoskeletal pain and ergonomic aspects of dentistry. Rev Dor São Paulo. 2015;16(2):90-5. doi: 10.5935/1806-0013. 20150018.

25. Keriri HM. Prevalence and risk factors of low back pain among nurses in operating rooms, Taif. Saudi Arabia Am J Res Commun. 2013:1(11):45-70

26. Golabadi M, Attarachi M, Raeisi S, Namvar M. Effects of psychosocial strain on back symptoms in Tehran general hospital nursing personnel. Arh Hig Rada Toksikol. 2013;64(4):505-12. doi: 10.2478/10004-1254-64-2013-2366.

27. Mosadeghrad AM. Relationship between nurses' knowledge about ergonomy and their job injuries. J Shahrekord Univ Med Sci. 2004;6(3):21-32.

28. Sadeghian F, Kalalian-moghadam H, Javanmard M, Khosravi A, Adelnia S. An epidemiological survey of low back pain and its relationship with occupational and personal factors among nursing personnel at hospitals of Shahrood Faculty of Medical Sciences. Iran South Med J. 2005;8(1):75-82

29. Mohseni-Bandpei MA, Fakhri M, Bargheri-Nesami M, Ahmad-Shirvani M, Khalilian AR, Shayesteh-Azar M. Occupational back pain in Iranian nurses: an epidemiological study. British J Nurse. 2006;15(17):914-7.

30. Choobineh AR, Rajaeefard A, Neghab M. Association between preceived demands and musculoskeletal disorders among hospital nurses of shiraz university of medical sciences:a questionnaire survey. Int J Occup Saf Ergon. 2006;12(4):409-16. doi: 10.1080/10803548.2006.1076699.
31. Choobineh AR, Movahed M, Tabatabaie SH, Kumashiro M. Preceived demands and musculoskeletal disorders in operating room nurses of shiraz city hospital. Ind Health. 2010;48(1):74-84.

32. Abedini R, Choobineh A, Hassanzadeh J. Musculoskeletal disorders related to patient transfer in hospital nursing personnel. J Health Sys Res. 2012;8(3): 385-96.

33. Eftekhar Sadat B, Babaei A, Amidfar N, Jedari EM. Prevalence and risk factors for low back pain in nursing staff of Tabriz in 1387. J Urmia Nurs Midwifery Fac. 2013:11(9):659-66.

34. Attarchi M, Raeisi S, Namvar M, Golabadi M. Association between shift working and musculoskeletal symptoms among nursing personnel. Iran J Nurs Midwifery Res. 2014;19(3):309-14.

35. Ghasemi GA, Rahimi N, Eshaghian M, Aghayari A. ThePrevalence of low BackPain and its correlation with some OccupationalFactors and demographic characteristics of the nurses working in the hospitals affiliated with social security organization inlsfahan, 2011. J Res Dev Nurs Midwifery. 2013;11(2):69-76.

36. Arsalani N, Fallahi-Khoshknab M, Josephson M, Lagerström M. Musculoskeletal disorders and working conditions among Iranian nursing personnel. Int J Occup Saf Ergon. 2014;20(4):671-80. doi: 10.1080/10803548. 2014.1077073

37. Pahlevan D, Aziz-zadeh M, Esmaili A, Ghorbani R, Mirmohammadkhani M. Association of Musculoskeletal complaints with psychosocial factors among nurses in Semnan hospitals. Middle East J Rehabil Health. 2014;1(1):e20841. doi: 10.17795/mejrh-20841

38. Rezaee M, Ghasemi M. Prevalence of low back pain among nurses: predisposing factors and role of work place violence. Trauma Mon. 2014; 19(4):e17926. doi: 10.5812/traumamon.

39. Nasiry-ZarrinGhabaee D, Haresabadi M, Bagheri-Nesami M, Esmaeili R, Talebpour AF. Musculoskeletal disorders in nurses and their relationship with occupation-related stress. J Mazandaran Univ Med Sci. 2015;25(132):91-102.

40. Dehdashti A, Mahjoubi Z, Salarinia A. Impact of nurse's work related body postures on their musculoskeletal disorders. Koomesh. 2015:16(3):338-46.

41. Habibi E, Farrokhi E, Mansourian M. Assessment of nurses' patient transfer technique with DINO method and compare it with MAPO method in estimation musculoskeletal disorders risk. J Prev Med. 2015;2(4):50-7.

42. Azma K, Hosseini A, Safarian MH, Abedi M. Evaluation of the relationship between musculoskeletal discomforts and occupational stressors among nurses. N Am J Med Sci. 2015;7(7):322-7. doi: 10.4103/1947-2714.161250.

43. Rokni M, Abadi M, Saremi M, MirMohammadi MT. Prevalence of musculoskeletal disorders in nurses and its relationship with the knowledge of ergonomic and environmental factors. J Gorgan Univ Med Sci. 2016;18(1): 128-32.

44. Taghinejad H, Azadi A, Suhrabi Z, Sayedinia M. Musculoskeletal Disorders and Their Related Risk Factors Among Iranian Nurses. Biotech Health Sci. 2016:3(1):e34473. doi: 10.17795/bhs-34473.

45. Saremi M, Khayati F. Evaluation of incidence of low back pain and its relationship with ergonomic risk level of wards among nurses. J Mod Rehabil. 2016;9(4):68-77.

\section{Submit your next manuscript to BioMed Central and we will help you at every step:}

- We accept pre-submission inquiries

- Our selector tool helps you to find the most relevant journal

- We provide round the clock customer support

- Convenient online submission

- Thorough peer review

- Inclusion in PubMed and all major indexing services

- Maximum visibility for your research

Submit your manuscript at www.biomedcentral.com/submit 